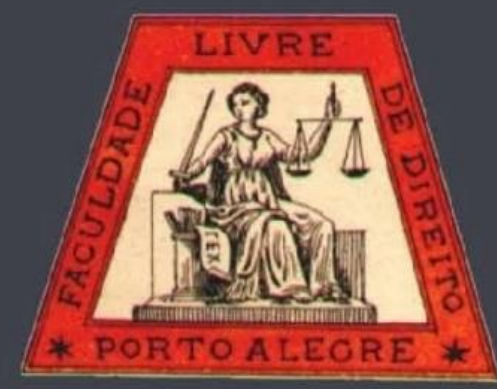

Para um reexame das noções de jusnaturalismo e direito natural

Towards a reexamination of the notions of jusnaturalism and natural law

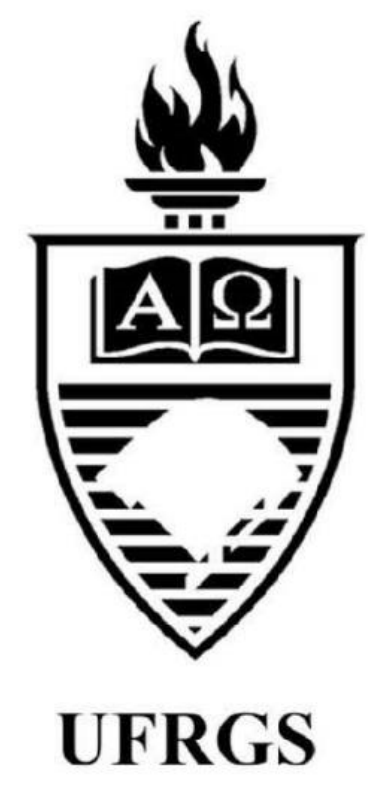

Sergio Cotta

Università La Sapienza di Roma 


\title{
Para um reexame das noções de jusnaturalismo e direito natural ${ }^{*}$
}

\author{
Towards a reexamination of the notions of jusnaturalism and natural law
}

Sergio Cotta**

\begin{abstract}
REFERÊNCIA
COTTA, Sergio. Para um reexame das noções de jusnaturalismo e direito natural. Revista da Faculdade de Direito da UFRGS, Porto Alegre, n. 36, p. 36-54, ago. 2017.
\end{abstract}

\begin{abstract}
RESUMO
Em meio à confusão moderna e contemporânea sobre o que é o direito, os vocábulos bimilenares "direito natural" e "jusnaturalismo" oferecem uma definição clara deste objeto, que, contudo, é fortemente repudiada desde o século XIX. Apesar disso, a relação entre direito e natureza permanece presente em diversos autores de matrizes filosóficas diversas. $\mathrm{Na}$ atualidade, o direito natural é reproposto na temática dos direitos humanos, de modo que está longe de ser uma ideia superada. Assim, reexamina-se criticamente os temas do direito natural e do jusnaturalismo, defendendo como critério de identificação do seu núcleo comum a estrutura epistemológica do jusnaturalismo - isto é, do saber teórico que estuda o direito natural -, apoiada nos elementos da problematicidade e de um fundamento originário e condicionante do ser do direito enquanto estrutura da vida prática: o eu-sintéticorelacional.
\end{abstract}

PALAVRAS-CHAVE

Direito natural. Jusnaturalismo. Eu-sintético-relacional.

\begin{abstract}
In the midst of the modern and contemporary confusion about what is law, the bimillenial words "natural law" and "jusnaturalism" offer a clear definition of this object, which, however, has been vigorously repudiated since the 19th century. In spite of that, the relationship between law and nature remains current in several authors from different philosophical backgrounds. Nowadays natural law is proposed again within the subject of human rights, so it is far from being an outdated idea. Thus, the author of this article reexamines critically the topics of natural law and jusnaturalism, arguing as the identification criterion of its common nucleus the jusnaturalism epistemological structure - that is to say, the theoretical knowledge on natural law -, based upon the elements of problematicity and of an original and determining foundation of the being of law in the quality of practical life structure: the relational-synthetic-I.
\end{abstract}

\section{KEYWORDS}

Natural law. Jusnaturalism. Relational-synthetic-I.
1. Heidegger escreveu: "Nenhuma época soube menos o que é o homem que a nossa"1. Seja exata ou inexata esta drástica sentença, não é de todo errado parafraseá-la dizendo, com maior cautela, que talvez nenhuma época tenha sabido menos o que é o direito que a nossa.
É uma prescrição heterônoma (à la Kant) ou a expressão normativa do comunitário Espírito do Povo (Savigny)? É a ordem (Austin) ou a prescrição (Bobbio) da autoridade; ou a decisão, quer do "soberano" (Schmitt), quer dos juízes (Holmes, Ross)? É a regra dos interesses (Jhering)

\footnotetext{
* Capítulo de COTTA, Sergio. Diritto, persona, mondo umano. Torino: Giappichelli, 1989, pc. 157-183. Tradução de Frederico Bonaldo (professor de Ética na Faculdade de Filosofia da Universidade Católica de Santos; professor assistente de Metodologia e Lógica Jurídica na Faculdade de Direito da PUC-SP; Doutorando em Direito na PUC-SP; Doutorando em Filosofia na UNIFESP; Mestre em Direito pela UERJ).

** O Prof. Sergio Cotta (1920-2007) foi um jurista e filósofo italiano. Ocupou a cátedra de Filosofia do Direito na Università La Sapienza di Roma de 1966 a 1990.

${ }^{1}$ HEIDEGGER, Martin. Kant e il problema della metafisica. Trad. M. E. Reina. Bari: Laterza, 1981, p. 181.
} 
ou uma regra sobre o uso da força (Kelsen, Olivecrona)? É um ordenamento, quer social (Santi Romano), quer formal (Kelsen), estendido até mesmo ao âmbito internacional ou uma constelação de ordenamentos fechados, autárquicos e autônomos, de unidade apenas lexical (Ross)? Alargando-se o olhar, ele é visto como os imperativos expressos na história, ora do Espírito, ora da cultura, ou como a superestrutura das relações de produção. E eu ainda poderia continuar.

Assim, no dizer de Kant, a definição do direito mostra-se como o caput mortuum dos juristas (mas também dos filósofos). Com efeito, numa disparidade tão heterogênea de teses e de teorias, parece perder-se todo ponto firme de referência (que não seja o extrínseco da sanção punitiva) capaz de orientar em direção a uma aceitável, se não incontrovertível, definição do direito em si. Não será talvez que isto ocorra por causa do ponto de vista empírico-fenomênico comum a essas teorias hoje imperantes?

Um ponto de referência firme, porém, é-nos oferecido por duas expressões famosas na história do pensamento. Refiro-me a "direito (ou lei) natural" - rica de um uso constante, mais que bimilenar, na cultura ocidental - e a "jusnaturalismo", termo com o qual se designa, em tempos mais modernos, a igualmente extensa teorização daquele direito. Em ambas as expressões, o conceito e a realidade existencial do direito relacionam-se diretamente à natureza e encontram nela a sua referência de fundo. A mensagem das duas expressões é límpida, ao menos na sua (aparente) simplicidade: o direito é compreendido a partir da sua relação com a natureza.

No entanto, é de conhecimento geral que a supramencionada relação foi drasticamente

\footnotetext{
${ }^{2}$ Veja-se, por todos, PIOVANI, Pietro. Giusnaturalismo ed etica moderna. Bari: Laterza, 1961.

${ }^{3}$ Basta esta passagem: "O homem não é por natureza [zoológica!] aquilo em que vive e habita o espírito de Deus;
}

repudiada do século XIX em diante. Desde então, difundiu-se a convicção de que "direito natural" e "jusnaturalismo" não têm nenhum significado real, e por isso nenhuma capacidade de interpretar a experiência jurídica concreta e de esclarecer o conceito do direito. Teriam uma legitimidade apenas histórica (e, por isso, historiográfica) no âmbito da metafísica ontológica clássica, cosmoantropológica e, mais em geral, na filosofia da objetividade. Mas para além desse âmbito histórico cultural já não teriam qualquer validade teorética, uma vez que as mencionadas filosofias teriam sido definitivamente superadas pela moderna filosofia da subjetividade e do historicismo ${ }^{2}$. Dito brevemente: o direito - e, por isso, tanto a ciência jurídica como a jusfilosofia não teria nada a ver com a natureza.

Seria uma empreitada demasiado longa e complexa delinear neste breve escrito um quadro adequado das várias correntes culturais (filosóficas e não filosóficas) que, ao entrecruzarse, levaram ao eclipse da relação entre direito e natureza. Assim, limito-me a poucas alusões muito concisas, de cujo caráter aproximativo sou plenamente consciente.

Da Escola histórica do direito ao positivismo jurídico, nas suas várias orientações, o direito perde a universalidade que lhe foi reconhecida pelo jusnaturalismo clássico e concretiza-se no ordenamento normativo de um povo ou de um Estado. Hegel, por um lado, confere significado filosófico a esta concepção; por outro lado, no plano da antropologia filosófica, Hegel identifica - com Kant e para além de Kant - a natureza do homem com uma liberdade indeterminada, que o eleva acima da determinística natureza zoológica ${ }^{3}$. Por parte do positivismo jurídico, o direito torna-se um mero instrumento da organização social em que o

o homem não é por natureza aquilo que deve ser. $\mathrm{O}$ animal é por natureza aquilo que deve ser" (HEGEL, Georg, W. F. Lezioni sulla storia della filosofia. Trad. E. Codignola e C. Sanna. Firenze: La Nuova Italia, 1947, I, 135). 
homem se realiza historicamente. O marxismo, por sua vez, vê-o como superestrutura mais ou menos ideológica das concretas relações de produção, destinada, aliás, a desaparecer na sociedade comunista, até mesmo "na sua forma mais geral como direito do homem"4.

Todavia, esta drástica cisão entre direito e natureza não pode suscitar perplexidade. Com efeito, é difícil negar a presença paralela, naquele mesmo período, de uma difundida atenção à natureza no seu significado para o homem: na filosofia (a Sexta sinfonia de Beethoven, os Lieder "noturnos" de Schubert sobre temas de Novalis), na poesia (de Hölderlin, Shelley e Leopardi a Rilke) como também na pintura (de Corot a Segantini, a Monet e até mesmo a Chagall). E bastam estes poucos nomes emblemáticos de várias orientações ou sensibilidades para mostrar que, na globalidade da cultura «de ontem», como S. Zweig a chamava, a consciência da relevância da natureza para a autocompreensão do homem não desapareceu.

Essa consciência não desapareceu; antes pelo contrário, talvez tenha se acentuado em tempos mais próximos a nós. A psicanálise, ao indagar sobre o psiquismo humano, pôs em evidência a diferença entre a natureza do homem e a do animal. Não obstante o seu declarado materialismo, Freud não hesitou em declarar: "Um abismo separa o indivíduo real do conceito de espécie"5. Jung, por sua vez, com a sua teoria do inconsciente coletivo, fez notar a presença neste dos arquétipos culturais. Por conseguinte, a natureza humana não é zoomórfica nem interpretável de modo zoológico, como aliás confirma a antropo-análise de Binswanger.

\footnotetext{
4 Cf. MARX, Karl; ENGELS, Friedrich. L'ideologia tedesca, III, 6, B, 2T corolário.

5 FREUD, Sigmund. L'Io e l'Es. Torino: Bollati Boringhieri, 1976, p. 57.

6 Veja-se, a propósito, LÖWITH, Karl. Critica dell'esistenza storica. Trad. A. L. Kunkler Giavotto. Napoli: Morano, 1967 e o meu L'uomo tolemaico. Milano: Rizzoli, 1975.
}

Por outro lado, o surgimento impetuoso da questão ecológica repropõe ao filósofo a questão da relação existencial entre homem e natureza ${ }^{6} \mathrm{e}$ confere renovada atualidade à concepção cosmoantropológica de Leibniz, não por acaso um firme defensor do direito natural.

Portanto, mostra-se muito problemática, de vários pontos de vista, a tese de que o direito (mas também a política e a moral) - para ser compreendido, elaborado conceitualmente e até mesmo produzido - não precisaria referir-se à relação homem-natureza, mas, pelo contrário, prescindir dela. Não será que, talvez, o hodierno "saber menos" de uma época acerca do que é o direito advenha do fato de se ter perdido ou abandonado preconceituosamente o rastro do direito natural, profundamente marcado na história da experiência humana e da teorização? A pergunta não é impertinente, no duplo sentido desta palavra.

Ademais, a ideia da possibilidade de um direito natural, e, por conseguinte, da legitimidade de uma teorização jusnaturalista, não desapareceu de todo nos dias de hoje. Além dos continuadores do jusnaturalismo clássico, essa ideia encontra-se explicitamente presente no positivismo de um Spencer ou de um Ardigò $^{7}$, no historicismo de E. Dilthey $^{8}$, no particular marxismo de Ernst Bloch e no positivismo jurídico moderado de H. L. A. Hart, que aceita um "conteúdo mínimo do direito natural" ". Além disso, transparecem elementos jusnaturalistas na psicanálise de Freud e de Jung (por meio da noção de "normalidade psíquica"), no existencialismo de Jaspers, assim como naquele existencialismo que chamo jusnaturalismo libertino hodierno - pense-se em Michel Foucault. No campo mais estritamente

${ }^{7}$ Vide, a propósito, os estudos de Alessandro LEVI em Scritti minori di filosofia del diritto. Vol. I. Padova: CEDAM, 1957.

${ }^{8}$ Sobre este, veja-se CALABRÒ, Gaetano. Dilthey e il diritto naturale. Napoli: Morano, 1968.

${ }^{9}$ Cf. HART, Herbert L. A. Il concetto del diritto. Trad. M. Cattaneo. Torino: Einaudi, 1965, p. 225-232. 
jurídico, H. Kantorowicz (não por acaso um dos maiores teóricos do "direito livre") reconheceu o valor das teorias jusnaturalistas para uma definição adequada do fenômeno jurídico ${ }^{10}$. Por fim, recordem-se ao menos duas obras recentes que, na cultura anglo-saxônica atual amplamente orientada para o positivismo e para a filosofia analítica - , sustentaram vigorosamente as razões da existência de direitos precedentes ao estabelecimento normativo e, de modo ainda mais explícito, dos direitos naturais. Refiro-me, no primeiro caso, a Taking Rights Seriously, de Ronald Dworkin, e, no segundo caso, a Natural Law and Natural Rights, de John Finnis.

Seja qual for o valor documental das indicações dadas até aqui de modo sumário ${ }^{11}$, fato é que a questão do direito natural é hoje reproposta de modo peremptório pelo tema teórico e prático dos direitos humanos. Sejam estes reconhecidos pelo direito positivo, como proclama a Constituição italiana (art. 2) ou instituídos pelo legislador, é difícil negar o seu caráter transcultural e (tendencialmente) universal, isto é, a sua referência ao homem, independentemente das diversas especificações culturais e normativas que se lhe conferem.

Por todas estas razões, mostra ser um erro, pelo menos de perspectiva, considerar o tema do direito natural - e, com ele, o do jusnaturalismo como definitivamente superado. Impõe-se, pelo contrário, a necessidade de reexaminá-lo criticamente. É o que me proponho a fazer agora.

2. Mas então, o que podemos entender por "direito natural"? Se dispuséssemos de uma atenta pesquisa de antropologia cultural que abarcasse $o$ âmbito temporal e espacial em que esta expressão tem sido usada, talvez pudéssemos chegar a uma conclusão válida, ao menos em relação ao modo

\footnotetext{
${ }^{10}$ Cf. KANTOROWICZ, Hermann. La definizione del diritto. Trad. Enrico di Robilant. Torino: G. Giappicchelli, 1962, p. 54-55.
}

como é interpretada pelo homem comum. Neste plano, não é aventurada a hipótese de que o direito natural seja entendido como o direito (no seu duplo aspecto de regra objetiva e reivindicação subjetiva) reconhecido espontaneamente como obrigatório e não como imposto de fato por uma autoridade investida de poder. Se a pesquisa supramencionada confirmasse esta hipótese, poder-se-ia extrair dela uma conclusão muito interessante para a reflexão teorética.

Mas essa pesquisa ainda não foi realizada, a não ser em fragmentos esparsos e, aliás, obscurecidos pela radical oposição entre natureza e cultura, geralmente aceita pela antropologia cultural. Portanto, para saber o que se entende ou se deve entender por direito natural é preciso dirigir-se à teoria que o tematizou e conceitualizou: ao jusnaturalismo.

No entanto, aqui já surge uma grave dificuldade. Não existe um único jusnaturalismo, mas muitos e nem sempre conciliáveis entre si. Portanto, se os jusnaturalistas não estão de acordo acerca do que é e do que prescreve o direito natural, parece lícito concluir que ele é uma ilusão emotiva (e consolativa) do homem comum, uma espécie de fantasma que os doutos se afanam em construir como um ente real. Ou então é - para usar a linguagem marxista - a superestrutura ideológica que mascara a estrutura material de certas relações de produção, a qual, de nenhum modo, é jurídica em si mesma. No máximo, podese atribuir ao direito natural a qualidade de um ideal do direito, mas não de um direito real. Estas são as objeções mais comumente dirigidas ao direito natural. Seja ele ou não um fantasma, uma superestrutura mais ou menos interessada ou um ideal jamais totalmente realizável, o fato é que a indiscutível diversidade das suas determinações estabelecidas pelos vários jusnaturalismos parece

${ }^{11}$ Para a Itália, veja-se a bela análise de MARINI, Giulano. Il giusnaturalismo nella cultura filosofica italiana del Novecento (1976), agora em Storicità del diritto e dignità dell'uomo. Napoli: Morano, 1987. 
tornar pouco crível a capacidade substancial da teorização jusnaturalista de deixar claro o que é o direito natural e, mais em geral, o direito. A este respeito, basta recordar a repetida crítica dirigida aos jusnaturalismos de, no passado, terem considerado a escravidão como de direito natural, a qual, hoje, é (quase) universalmente reconhecida como desumana.

Pode-se replicar, com efeito, que se encontram diferenças e pontos inconciliáveis também no campo da filosofia em geral, sem que por isto se chegue a repudiá-la, a não ser por parte de um ceticismo vulgar. Mas não é conveniente desembaraçar-se tão facilmente da objeção. A meu ver, é indispensável constatar preliminarmente se há uma característica comum que confere uma unidade de fundo aos vários jusnaturalismos, independentemente das suas diferenças, e que, portanto, constitui o núcleo da teorização jusnaturalista. Sobre esse núcleo - se é que existe -, enfoca-se uma correta discussão sobre a legitimidade dessa teorização e, por isso, sobre a sua capacidade de definir o direito natural, independentemente do fato histórico, ainda que relevante, do seu "eterno retorno", como foi dito por H. Rommen, com uma fórmula afortunada ${ }^{12}$.

Mas então qual é o critério para identificar o núcleo comum? Forneço rapidamente o campo de soluções que considero insatisfatórias, por se basearem em aspectos parciais ou controversos. 1) Não considero satisfatório o critério - embora constante - referência à natureza. Trata-se da natureza em sentido naturalista de Ulpiano (quod omnia animalia docuit), pulsional de Foucault ou da natureza própria do homem? Ademais, entre a natureza humana segundo $S$. Tomás e a natureza humana segundo Hobbes ou Spencer há diferenças profundas, que levam a determinações normativas amplamente estendidas. 2) Não considero satisfatório o critério substancial dos conteúdos atribuídos ao direito natural, pois, com frequência, são demasiado diversos entre si e por vezes opostos, como no caso já lembrado da escravidão. 3) Não considero satisfatório o critério da forma social conforme ao direito natural; há um jusnaturalismo coletivista, um individualista, um comunitário. A concepção da propriedade talvez seja o divisor de águas mais nítido entre eles. 4) Não considero satisfatório o critério da função do direito natural: há um jusnaturalismo coletivista, um individualista, um comunitário. A depender da concepção da ordem conforme a natureza, tem-se um jusnaturalismo conservador e um revolucionário, e, em chave mais especificamente política, um que privilegia a autoridade e outro que privilegia a liberdade. 5) Por fim, tampouco considero satisfatório o critério da orientação filosófica: há um jusnaturalismo racionalista e um vitalista.

A meu ver, o critério válido é o da estrutura epistemológica do jusnaturalismo, que não desconhece a variedade das suas doutrinas históricas, mas as enquadra como um modo específico de proceder da teorização jurídica. Essa estrutura é conotada por dois elementos que me parecem presentes de forma mais ou menos explícita em qualquer jusnaturalismo.

O primeiro elemento é o da problematicidade, e não o da dogmaticidade, como muitas vezes se afirma. Com efeito, o jusnaturalismo é problematização do dado meramente factual e fenomênico do ser do direito.

Não por acaso, nas suas origens dentro da cultura ocidental, ele surge na Grécia problematizando a ingênua e primitiva atribuição da naturalidade apenas ao ordenamento jurídico vigente da própria comunidade particular, isto é, às próprias regras ancestrais de costume. Assim, o jusnaturalismo (ocidental) surge da problematização do sentido imediato e

\footnotetext{
12 Cf. ROMMEN Heinrich. L'eterno ritorno del diritto naturale. Trad. Giovanni Ambrosetti. Roma: Studium, 1965.
} 
particularista da naturalidade do direito. Isto não é paradoxal, uma vez que é um dado histórico seguro que se reproduzirá por ocasião da descoberta da América, quando a reflexão jusnaturalista, em especial a espanhola, chegará a criticar a identificação do direito natural com o direito da tradição europeia. Ademais, a problematização operada pelo jusnaturalismo continua a ser exercitada ao longo dos séculos por meio da tarefa de racionalização - e de consequente análise crítica - do direito (tanto do seu conceito como das suas normas) tal como se apresenta no seu ser fenomênico.

O segundo elemento caracterizador, coerente com o primeiro - aliás, consequente a ele -, é a busca de um fundamento originário $e$ condicionante do ser do direito entendido como estrutura da vida prática. De fato, se a redução do direito ao seu ser fenomênico suscita problemas para a sua plena compreensão, então essa compreensão não pode reduzir-se à descrição sobre como o direito se apresenta no plano empírico-factual, nas suas várias articulações: leis, contratos, sentenças, penas, instituições etc. O jusnaturalismo não é descritivo - mas não por isto é imediatamente valorativo - do direito vigente; o seu intuito primário é explicativo. $\mathrm{Ou}$ seja, enfrenta problematicamente a pergunta "por $q u \hat{e}$ ?" existe o direito-fenômeno, presente em todas as culturas e em todos os tempos. Assim, esse seu ser fenomênico é transcultural e transtemporal, e por isso não é plenamente explicável sem a constatação de um fundamento não meramente contingente e particular, mas ínsito à condição humana. Independentemente dos resultados, é uma busca comum a jusnaturalismos tão diversos entre si como, por exemplo, os de S. Tomás e de Hobbes.

A estrutura epistemológica problemáticofundamentadora do jusnaturalismo esclarece a sua natureza (de reflexão) filosófica e, em certo sentido, exclui que seja uma doutrina puramente assertória, que traz consigo o risco de cair no ideologismo. De outro ponto de vista, diferenciao da ciência jurídica descritiva e sistematizadora dos dados fenomênicos, sem por isto opor-se a ela ou negá-la, uma vez que se situa num nível cognoscitivo mais profundo.

O discurso desenvolvido até aqui mostrou a unidade e a legitimidade epistemológicas do jusnaturalismo como filosofia, mas não visava nem podia - corroborar os seus resultados. Para este fim é necessária uma ulterior exploração dentro do jusnaturalismo, para que se veja se ele, dentro do quadro epistemológico traçado, oferece um específico procedimento ou modelo de investigação válido para a compreensão substancial do direito. Considero que sim. A meu ver, o típico procedimento explicativo e argumentativo do jusnaturalismo articula-se essencialmente em três tempos.

O primeiro tempo é constituído pela detecção e aceitação do atributo geral e genericamente reconhecido (inclusive pela ciência jurídica) ao direito empírico: a obrigatoriedade objetiva das suas regras. Outras regras mostram-se como possuidoras de uma obrigatoriedade apenas subjetiva: as de amizade, por exemplo, mas também as morais, pelo menos segundo uma orientação muitíssimo discutível, ainda que muito difundida na cultura contemporânea.

O segundo tempo tem início com a problematização dessa reconhecida obrigatoriedade objetiva: por que o direito é obrigatório? A esta pergunta dá-se a seguinte resposta: a obrigatoriedade do direito depende da sua justiça. A concisa afirmação de S. Agostinho pode ser considerada sintetizadora dessa plurissecular posição jusnaturalista: o dever (officium) de obedecer à lei depende do "non esse lex quae iusta non fuerit"13. Todavia, a justiça

${ }^{13}$ AGOSTINHO HIPPONENSIS. De libero arbitrio, I, 5, 11. Trad.: "Não é lei aquela que não for justa". 
também pode ser pensada de modo objetivo ou subjetivo, como ocorre em alguns jusnaturalismos - ambíguos, aliás -, como o de Hobbes, para quem a justiça extrai a sua determinação da vontade subjetiva legiferante do soberano.

O terceiro tempo esclarece o ponto: é justo, e por isto obrigatório, o direito conforme a natureza, fundamentado na natureza, o direito natural. Este último não é eliminado de todo nem sequer no ambíguo jusnaturalismo de Hobbes, não obstante o seu voluntarismo, que antecipa $o$ juspositivismo contemporâneo. De fato, no pensamento de Hobbes, o natural direito do indivíduo à sobrevivência permanece até mesmo na vigência do direito positivo estabelecido pela autoridade; além disso, a lei natural é lei suprema das relações interestatais. Mais do que nunca, o direito natural estava ausente no jusnaturalismo sui generis de Cálicles - para quem, segundo Platão, a natureza estabelece a supremacia do mais forte - ou, mais modernamente, no anômalo jusnaturalismo de Nietzsche, inspirador do hodierno jusnaturalismo libertino. Com efeito, se a justiça é o produto da vontade de poder, como Nietzsche afirma explicitamente ${ }^{14}$, essa vontade é para ele natural; aliás, é a característica da Natureza mesma, no seu perene movimento de criação-destruição.

O segundo tempo do procedimento explicativo jusnaturalista caracteriza-o com relação às teorias antigas e modernas, que fundamentam ou argumentam a obrigatoriedade do direito na sua utilidade, mais ou menos maximizada; pense-se em Bentham e nos seus seguidores atuais. O terceiro tempo, por sua vez, diferencia-o das teorias que sustentam que a obrigatoriedade das normas ou do ordenamento depende da sua eficácia psicológica ou coativa. Todavia, a necessária alusão aos jusnaturalismos ambíguos ou anômalos - aqui limitados aos casos exemplares de Cálicles, Hobbes e Nietzsche - corre o risco de repropor a costumeira conclusão cética acerca do poder heurístico do jusnaturalismo. Qual natureza e, consequentemente, qual direito natural? Se a natureza dá origem - e por isto confere justiça tanto à ordem do poder como ao poder da ordem, então o direito natural reduz-se realmente a um Proteu inapreensível.

3. Deixo de lado por enquanto a questão da natureza e detenho-me na questão da obrigatoriedade do direito. Como eu já disse, os juristas (teóricos e práticos) reconhecem-na como característica essencial do direito, embora difiram ao identificar a sua origem. Pois bem, se se reconhece alguma verdade à mensagem semântica do uso linguístico (e o jurista não precisa recorrer à autoridade de Heidegger para reconhecê-lo), deve-se então concluir que há uma diferença radical entre "obrigar" e "impor" ou, mais ainda, "constringir". Leibniz, aliás, insistiu várias vezes sobre este ponto. Com efeito, a palavra "obrigação" indica um dever fazer (ativo ou abstido), e por isso a assunção consciente desse dever; a imposição, por sua vez, indica um não poder não fazer aquilo que é imposto, e por isso a submissão por causa de impotência. A mensagem semântica das duas palavras reflete dois modos existenciais em nada coincidentes, mas, antes pelo contrário, opostos.

Porém a obrigatoriedade da norma jurídica não está implícita em nenhuma das características exteriores com as quais ela se apresenta e que lhe são reconhecidas por juristas e filósofos. Não está implicada nas características formais - tais como derivação da vontade do legislador ou de uma norma fundamental, pertença a um ordenamento e forma prescritivo-sancionadora - e menos ainda nos materiais - tais como pressão psicológica, uso efetivo da força sancionadora ou punitiva. Não por acaso, desde quando se olhou para a norma

${ }^{14}$ Cf. NIETZSCHE, Friedrich. Die Unschuld des Werdens, II, p. 262, na edição Kroener. 
jurídica somente sob estes aspectos exteriores, ela foi qualificada como heterônoma, e, por consequência lógica, como impositiva. Portanto, não é obrigatória, ou seja, é uma norma (em sentido genérico) cujo destinatário tem a possibilidade - aliás a liceidade (não hesito em dizê-lo) - de eludi-la tão logo a sua impotência cesse. Isto vale também no caso em que o direito é considerado não já como pura e simples força impositiva, mas como "regra sobre o uso da força"15.

Nessa perspectiva, porém, a norma jurídica não se distingue de modo algum da prescrição de uma associação criminosa, tal como uma longa tradição, de S. Agostinho a Leibniz, fez notar criticamente. Todavia, não são poucos - até mesmo entre os estudiosos - que as consideram indistinguíveis apenas no plano meramente factual. Basta recordar aqui a opinião de Kelsen, que, na última edição da Teoria pura do direito ${ }^{16}$ confia a distinção ao instável critério da eficácia impositiva do poder, que, de per si, é sempre mutável e, por isto, incompatível não só com a certeza do direito, mas também com a estabilidade de um ordenamento jurídico. Nem a sua póstuma Teoria geral das normas, em que a questão não é mais tratada especificamente, traz uma mudança de posição; com efeito, se "a norma é o sentido de um querer, de um ato de vontade [...] dirigido ao comportamento alheio" 17 , esta definição aplica-se perfeitamente à prescrição do criminoso. Mas esta conclusão é impugnada pela experiência comum e sensata: é precisamente em face da imposição que o indivíduo reivindica o próprio direito!

Não leva a um resultado mais satisfatório a recondução da obrigatoriedade da norma jurídica à sua utilidade ou a um oportuno exercício da prudência, no sentido de que a prudência induz a reconhecer a obrigatoriedade da norma. $\mathrm{Na}$

\footnotetext{
${ }^{15}$ É a tese a que adere Norberto BOBBIO em "Diritto e forza", em Studi per una teoria generale del diritto. Torino: G. Giappichelli, 1970, p. 119-138.
}

realidade, a utilidade e a prudência, se são motivos muito influenciadores para induzir à obediência, não são necessariamente provas suficientes do reconhecimento da obrigatoriedade da prescrição; tanto é assim que elas influenciam também o comportamento de quem, por impotência ou temor, se submete à imposição criminosa ou ilícita. Não por acaso, uma sagaz doutrina teológico-moral, para fazer frente ao arbítrio do poder político, introduziu - junto à categoria das leis possuidoras de força obrigatória, porque justas - a categoria das leges mere poenales válidas quanto à forma, mas não quanto à substância, às quais é oportuno obedecer, mas não obrigatório. Poder-se-á discutir a aplicação prática que se tem feito desta última categoria, mas não a sua correição teorética, que se refere à distinção entre obrigação e imposição.

Certamente, há uma fundamentação da obrigatoriedade do direito que não apela para os seus aspectos formais e materiais, mas para a sua dimensão espiritual ou, mais genericamente, cultural, de maneira que o resguarda da crítica sobre a sua indistinguibilidade em relação à ordem criminosa. É a fundamentação historicista, já não mais própria apenas de uma determinada filosofia, mas difundida também na cultura comum e compartilhada, pro suo modo, por uma grande parte da antropologia cultural hodierna. A obrigatoriedade dependeria da conformidade das normas aos valores, mas a valores históricos, resguardados da subjetividade da sua criação ou assunção por causa da sua correspondência com o "sentido da história". O direito conforme o sentido da história seria, portanto, obrigatório. A tese é sugestiva e deve o seu êxito à influência das filosofias modernas da história, entendida quer como progresso, quer como subversão da práxis.

${ }^{16}$ Cf. KELSEN, Hans. La dottrina pura del diritto. Trad. Mario G. Losano. Torino: Einaudi, 1960, p. 57-61.

${ }^{17}$ Idem. Teorie generale delle norme. Trad. Mirella Torre. Torino: Einaudi, 1985, p. 4. 
Mas o "sentido da história" proposto por essas filosofias é mais fácil de ser falsificado que verificado, a não ser... no fim da história. Porém, nesse tempo terminal, só poderia verificá-lo Quem estivesse fora da história. Ademais, as detecções do sentido da história, para além de uma banal generalidade, resultam contraditórias entre si. Marca o triunfo da ciência-indústria de Comte ou da liberdade ético-política de Croce? Do Estado-comunidade de Hegel ou da sociedade comunista de Marx? Por isso, a obrigatoriedade do direito existente de fato permanece sempre precária e discutível, a menos que não se queira sustentar que o direito é obrigatório porque existe de fato, retornando assim à confusão entre obrigatoriedade e eficácia, e caindo de modo evidente na forma extrema da falácia naturalista.

Além disso, a inconclusividade das supramencionadas fundamentações da obrigatoriedade do direito não pode fazer que se desconheça que ela é a característica essencial do direito, a não ser que se desconheça o sentido existencial deste. Nesse caso, seria impossível dar razão da sua peculiar presença transcultural e transtemporal.

Ademais, a experiência jurídica concreta atesta claramente a necessidade de justificar a obrigatoriedade das normas. Se na perspectiva jusnaturalista a obrigatoriedade das normas era (e é) demonstrada com base na sua conformidade com o direito natural, também num ambiente juspositivista ela não é poupada dessa tarefa. A exposição de motivos que acompanha a proposta de uma lei ou a motivação que sustenta o dispositivo das sentenças judiciárias ${ }^{18}$ são precisamente a demonstração ou a argumentação (mais ou menos bem-sucedida) não apenas da oportunidade da norma, mas, sobretudo, das

\footnotetext{
${ }^{18}$ Sob pena de impugnação ou de nulidade no ordenamento jurídico italiano: art. 360 do CPC; art. 385 e 475 do CPP.

${ }_{19}$ Veja-se a propósito SCARPELLI, Ugo. Gli orizzonti della giustificazione. Rivista di Filosofia, 1985, p. 1-50.

${ }^{20}$ Cf. COTTA, Sergio. Giustificazione e obbligatorietà delle norme. Milano: Giuffrè, 1981 e IDEM. Il diritto
}

razões da sua obrigatoriedade. $\mathrm{O}$ operador jurídico - legislador, juiz, intérprete - tem clara consciência de dever justificar a obrigatoriedade objetiva - erga omnes - da norma mediante um discurso racional referido à realidade que se pretende regulamentar. Em suma: não há obrigatoriedade do direito sem justificação. Só esta última - se for válida - é capaz de resguardar o direito do qualificativo de imposiçãoconstrição, que frustra o seu específico sentido existencial.

De resto, a exigência de justificar tanto as escolhas morais como as normas jurídicas já se impôs - e isto é significativo - até mesmo entre os defensores da "grande divisão" entre cognitivismo e não-cognitivismo ético. Com efeito, já são muitos e autorizados entre estes os que consideram indispensável sustentar com "boas razões" argumentativas os valores e as escolhas de valor, às quais continuam a atribuir (a meu ver, de maneira não de todo convincente) uma origem subjetiva ${ }^{19}$.

Tudo o que eu disse até agora e tudo o que direi a seguir resume e integra em alguma medida o exame mais amplo da relação entre justificação e obrigatoriedade das normas que desenvolvi em trabalhos precedentes ${ }^{20}$. Por isso, limito-me aqui ao essencial e aos desenvolvimentos que me pareceram necessários.

A justificação de uma norma - isto é, do enunciado que estabelece um dever, uma obrigação de modo prescritivo ou constitutivo ${ }^{21}$ encontra, a meu ver, o seu fundamento válido primeiramente no plano do ser existencial. Nesse plano, não se incorre na conhecida acusação de "falácia naturalista", que, sem dúvida, é válida no plano lógico-proposicional, se, de fato, não é possível transformar uma proposição alética ou

nell'esistenza: Linee di ontofenomenologia giuridica. Milano: Giuffrè, 1985, cap. 7.

${ }^{21}$ Sobre isto veja-se CARCATERRA, Gaetano. La forza costitutiva delle norme. Roma: Bulzoni, 1979. 
de ser numa proposição deôntica ou de dever ser - melhor: de dever fazer. Mas, na vivência concreta da experiência pessoal, todo dever é assumido pelo eu com referência mais ou menos lúcida à realidade de necessidades cuja satisfação é considerada essencial para a realização de si mesmo, para a superação da própria indigência individual. Esta realidade constitui o elemento alético sobre o qual se fundamenta o sentido subjetivo do dever na sua força obrigatória. Uma reflexão mais aprofundada mostra que indigência e necessidade de superá-la são características ontológicas do homem, e que revelam a relacionalidade coexistencial deste ${ }^{22}$. Portanto, é a relacionalidade coexistencial constituinte da verdade do ser-homem sobre a qual se fundamentam os deveres objetivos (isto é, válidos para todo indivíduo humano), para além do seu sentido puramente subjetivo.

Isto posto, delineio com um primeiro exemplo o procedimento mediante o qual considero possível e correta a justificação da obrigatoriedade das normas em termos de verdade. Dê-se hipoteticamente a norma "todos os cidadãos devem observar as leis do Estado"; não há dúvida de que o Estado, entendido como comunidade política, é uma das mais difundidas formas coexistenciais. Assim sendo, a norma supramencionada será justificada se, e somente se, for necessária para o ser da forma coexistencial "Estado". No Críton, Sócrates demonstrou-o com um raciocínio verídico, confirmando-o com o seu comportamento: se os cidadãos não observam as leis do Estado, este não subsiste $^{23}$. No lugar do Estado, surgiria a anarquia - numa guerra civil, não se sabe qual lado é o Estado, não em sentido meramente formal, mas substancial - ou, no limite, a inexistência de pátrias.

\footnotetext{
${ }^{22}$ Cf. COTTA. Il diritto nell'esistenza, op. cit., cap. 3 .

${ }^{23}$ PLATÃO. Críton, 50b e 53a. Na realidade, Sócrates faz uso principalmente de uma justificação de tipo axiológico, fundamentada no valor superior da pátria; mas isso não tira autonomia lógica à justificação alética a que me referi.
}

Indubitavelmente, isso não impede que se possa negar valor ao Estado em geral ou a um Estado determinado, e, assim, negar valor às leis estatais em geral ou em particular. Mas esses juízos de valor pressupõem o ser do ente sobre o qual são pronunciados, de maneira que não invalidam a correição da justificação proposta acima. É o ser - e o subsistir - do ente simbólicoexistencial Estado que implica que se observem as suas leis.

Digamos então em geral: o direito como categoria (e, por isso, nas suas normas) extrai a justificação da própria obrigatoriedade - ou deonticidade objetiva - da constatação alética da sua necessidade para o ser da forma coexistencial a que se refere. Essa justificação - que tem como premissa um juízo alético de existência, do qual extrai o necessário dever correspondente - é de todo independente do juízo de valor acerca da forma coexistencial em questão. O juízo axiológico não é o pressuposto da verdade constatada nem o fundamento último da obrigatoriedade da norma, e muito menos descende da existência desta, como Kelsen sustenta $^{24}$. O juízo de valor é o elo intermediário - normalmente implícito - que, no raciocínio justificativo, liga o juízo alético de existência à norma.

A minha exposição esquemática do procedimento de justificação da obrigatoriedade do direito encontra respaldo numa importante tese de Husserl. Ela permite que eu apresente um modelo de justificação plenamente consoante com o antigo raciocínio socrático e de possibilidade de desenvolvimento ainda mais ampla. Nas suas Investigações lógicas, Husserl escreve que as normas "devem ter um conteúdo teorético cindível do conceito de estabelecimento

${ }^{24}$ Cf. KELSEN. Teorie generale delle norme, op. cit., p. 335: "Um juízo de valor é sensato desde que e apenas quando está relacionado com uma determinada norma. Se é válida a norma $[. .$.$] o juízo de valor [\ldots]$ é verdadeiro". 
[de dever ser]"25. E precisa que a norma "Um A deve ser B" equivale à ("baseia-se em", diria eu) proposição teorética "Somente um A que é B é um bom A". Para ilustrar a sua tese, Husserl aduz o seguinte exemplo: "Um guerreiro deve ser corajoso' significa [...] que somente um guerreiro ‘corajoso' é um bom guerreiro" 26 . Há uma evasão ou pelo menos uma ambiguidade no discurso husserliano $^{27}$, que decorre de ele ter usado expressões axiológicas como "bom A", "bom guerreiro" e "corajoso".

Mas, a meu ver, a supramencionada evasão é superável se reformulamos o seu exemplo do seguinte modo: "O soldado deve (tem a obrigação de) combater, senão não é um soldado". O ser da modalidade existencial "soldado" ou potencial combatente (juízo alético de existência) fundamenta a norma "o soldado deve combater" - obviamente em tempo e lugar determinados, senão essa modalidade existencial se dissolveria. Ter-se-á, por sua vez, um bom soldado (juízo de valor) se este for hábil no uso das armas, corajoso, disposto a não se render etc. Mas esse juízo axiológico pressupõe a existência da figura do "soldado"; com efeito, não teria sentido pronunciá-lo referindo-se a um civil. Para ser soldado no sentido existencial da palavra basta ser aquele que é, ou seja, que está à disposição para combater, ainda que sinta medo durante o combate e não seja um bom soldado. Mesmo neste caso, a justificação da norma em questão nada diz ou prejulga acerca do valor a atribuir-se ao ser do soldado. A objeção de consciência ao serviço militar é prova disso.

Reformulo, portanto, a asserção geral de Husserl (válida também para a posição de Sócrates) do seguinte modo: "A deve ser $\mathrm{B}$ se, e somente se, B é necessário ao ser de A". Em outros termos: o comportamento devido de B tem o seu fundamento na verdade existencial de A,

25 Cf. HUSSERL, Edmund. Ricerche logiche. Vol. I. Milano: Mondadori, 1968, p. 54 e 57.

${ }^{26}$ Para as duas últimas citações, vide ibidem, p. 58 e 57. seja este o cidadão de Sócrates, o soldado de Husserl ou aquele que pertença a qualquer modalidade existencial. Uma fórmula de todo correspondente - mas mais articulada - permite pôr em evidência a concatenação entre juízo de existência, juízo de valor e prescrição normativa. Proponho a seguinte fórmula: "Se o comportamento $\mathrm{C}$ é necessário (contrário) ao ser da modalidade existencial $\mathrm{E}$, então tem (não tem) o valor $\mathrm{V}$ relativamente a $\mathrm{E}$, de modo que deve ser prescrito (proibido) pela norma N". O valor de E não é prejulgado, mas precisa ser justificado, senão se cai no puro subjetivismo dos valores.

4. Recorde-se agora o que eu disse anteriormente a propósito da articulação típica do discurso jusnaturalista. Este estabelece a obrigatoriedade das normas com base na sua justiça e determina esta última com base na sua conformidade com a natureza. Pois bem, o modelo de justificação que propus (respaldado por Sócrates e por Husserl!) não fez senão esclarecer o procedimento mediante o qual se pode demonstrar - com um discurso racional que liga o dever com a verdade existencial a que aquele se refere - a dependência da obrigatoriedade da justiça. Mas pode demonstrar que a obrigatoriedade da justiça depende da natureza? Considero que sim, uma vez que não é incorreto denominar "natureza" a estrutura constitutiva de um ente existencial, graças à qual este último é conotado em relação ao nada do seu ser. Essa natureza - como tenho procurado mostrar - é o fundamento do comportamento justo e da norma justa, e por isto obrigatória, sob pena da negação ou da dissolução do ente em questão. Nesta perspectiva, é lícito falar de direito natural em geral.

O procedimento justificativo que se ilustrou consiste num discurso racional, mas não

${ }^{27}$ A ela aponta a crítica de Kelsen (cf. Teoria generale delle norme, op. cit., p. 334-336), mas com demasiada pressa. 
racionalista, no sentido de uma dedução de um princípio ou de um valor apriorísticos. Pelo contrário, tem o seu ponto de referência indispensável no ser de um ente existencial, do qual, mediante a análise fenomenológica, se consegue identificar a estrutura ontológica peculiar, isto é, o ser do ente mesmo. Daí se segue que o direito natural não é ou não é pensado como um direito ideal ou puramente teórico, nem um direito naturalista assimilável às chamadas leis da natureza. Pelo contrário, é o direito justificado (doutrinariamente e/ou concretamente) na sua obrigatoriedade, para a sua correspondência com a natureza ou estrutura do ente a que se refere. Neste preciso sentido, considero que se pode falar de direito natural vigente, como Capograssi já fizera $^{28}$.

Neste ponto, impõe-se uma precisão importante. Os exemplos que aduzi até agora permitem pôr em evidência aquilo que chamo direito natural particular, por ser relativo a um âmbito ou forma existencial particular, não apenas por causa da sua consistência empírica, mas mais profundamente por causa da sua específica estrutura ontológica. Neste sentido, pode ser útil a distinção (só em parte rastreáveis nas Ideen de Husserl) entre ontologias regionais e ontologia universal. Particular é a forma existencial "Estado" e ainda mais a que se pode definir como status militar; portanto, são particulares os seus direitos naturais (isto é, justificados), assim como é particular o direito natural da família, extraível da sua análise ontofenomenológica $^{29}$. Portanto, não são formas exaustivas de toda a existência, como nos mostra a experiência, talvez antes mesmo da teorização.

Mas a constante aspiração primária do jusnaturalismo é determinar, sobretudo, um direito natural universal e absoluto. E este não

\footnotetext{
${ }^{28}$ Sobre este ponto e sobre as articulações do direito natural vigente, veja-se o meu Giustificazione e obbligatorietà delle norme, op. cit., p. 132-134.

${ }^{29}$ Mas, atente-se, a particularidade da família e do seu direito não é medida em relação ao Estado, como se faz com
}

pode deixar de ser o objetivo exigido pela compreensão integral da obrigatoriedade própria do direito em geral. Basta recordar um delicado problema posto no plano empírico. Que obrigatoriedade têm as normas e até mesmo todo o ordenamento jurídico de um Estado, ainda que justificados em relação ao ser deste último, se entram em conflito com o ordenamento jurídico ou com as normas da comunidade internacional que também tenham sido justificados em relação ao ser da comunidade internacional? Aqui, como é claro, não se trata de constatar qual dos dois ordenamentos consegue fazer-se respeitar; esta é uma (desconsoladora) quaestio facti, e não iuris, que não resolve em absoluto o problema jurídico (e moral!) teorético.

Em linha de princípio, considero possível chegar à determinação de um direito natural em nada abstrato ou ideal, e tampouco deduzido de valores a priori, mas que corresponda ao núcleo central de uma ontologia fundamental e não somente regional. Recorro mais uma vez a exemplos, que, contudo, se encaixam perfeitamente nas duas fórmulas gerais de justificação que propus acima. Considere-se por hipótese a seguinte norma: "Deve-se respeitar quem é inocente", cuja implicação, em termos de proibição, é: "Não se deve causar ofensa ou dano ao inocente". Pois bem, parece-me evidente que se esse respeito vem a faltar totalmente, a coexistência dissolve-se; se falta em parte, a coexistência é precária. Mas a coexistência é aquilo que caracteriza a condição humana ${ }^{30}$, de modo que, por isto, é o contexto existencial supremo, além do qual não há outro. Portanto, a norma em questão é obrigatória de modo universal e absoluto por causa da sua referência ao contexto existencial supremo, revelador da relacionalidade ontológica do homem.

demasiada frequência qualificando-a de modo simplista como uma "sociedade intermediária"; antes, é medida em relação à universal "família" humana.

${ }^{30} \mathrm{Cf}$. COTTA. Il diritto nell'esistenza, op. cit., cap. 3 e passim. 
Considere-se, também hipoteticamente, uma outra norma: "Não se deve plagiar pessoa alguma", em que o termo "plagiar" denota a subordinação do sentir e do querer alheio ao próprio $^{31}$. Parece-me claro que o plágio reduz o outro à sua pura animalidade e, por isto, expele-o da categoria ontológica a que pertence, a saber, a do ser-homem. É a referência alética a esta categoria que torna válida a justificação da obrigatoriedade universal e absoluta da norma em exame. Estes dois exemplos confirmam a diferença radical entre obrigação e imposição: tanto o dano causado ao inocente como o plágio são possíveis no plano da imposição, mas não comportam em absoluto a obrigação de submeterse a eles. As normas que os proíbem são, por sua vez, obrigatórias e de direito natural universal e absoluto. Mas esse direito não se limita as supramencionadas normas generalíssimas e de princípio. Estas, com efeito, sustentam impliciter a trama essencial do direito positivo e esclarecem o seu sentido. O direito penal, sobretudo - mas não só ele -, baseia-se na primeira norma, da qual extrai o seu fundamento a complexa e detalhada articulação das suas proibições: da difamação à calúnia, das lesões corporais ao homicídio. A noção de inocência sustenta inclusive os sistemas processuais, quer civil, quer penal. Na segunda norma baseiam-se o direito civil e o canônico pense-se nas disposições acerca dos vícios da vontade ou os relativos aos menores e aos incapazes -, bem como, novamente, o direito penal, na atenta determinação do elemento voluntarista nos atos criminosos. Estas poucas alusões são suficientes para indicar que é possível reconduzir a direito natural, no sentido que indiquei, uma grande parte do direito positivo.

\footnotetext{
${ }^{31}$ Esta norma não é hipotética em absoluto. Cf. o art. 603 do $\mathrm{CP}$, que definia o plágio como redução de outros "em total estado de sujeição" e lhe estabelecia uma pena. Nota do tradutor: no Direito brasileiro, o delito de plágio no sentido indicado acima está tipificado no art. 149 do Código Penal como crime de redução a condição análoga à de escravo, cuja redação é a seguinte: «Reduzir alguém a condição análoga à de escravo, quer submetendo-o a trabalhos
}

As duas normas acima assumidas como hipotéticas revelaram-se implícitas fundamentalmente no sistema do direito positivo. Mas elas têm uma capacidade heurística ainda maior: com efeito, permitem-nos chegar, por fim, ao núcleo da questão do direito natural. A propósito, dissolve-se, porém, um grave equívoco: o direito natural tem sido rejeitado por uma difundida cultura moderna principalmente por esta vir atribuindo ao termo "natureza" um significado estreitamente naturalista-biológico, ou, com Hobbes, até mesmo zoológico. A natureza assim entendida - para usar as palavras de Kant - é o reino da necessidade, ao qual se opõe o reino humano da liberdade e dos fins. $\mathrm{Na}$ mesma direção de pensamento, a antropologia cultural hodierna opõe natureza e cultura. E uma vez que o direito pressupõe a liberdade e pertence ao âmbito da cultura, a expressão "direito natural" é considerada autocontraditória: um ferro de madeira.

Mas a natureza a que o jusnaturalismo se refere é a do homem, e não a das coisas ou dos animais, aos quais precisamente Kant - de algum modo jusnaturalista ou ao menos tachado como tal por causa da sua Metafísica dos costumes considerava inaplicável a relação jurídica de deveres e direitos. A natureza do homem implica, sim, a liberdade, e, por isto, a escolha, mas com a condição intransponível de que estas, no seu exercício, não suprimam aquilo que as tornam possíveis: o ser do homem na sua específica estrutura ontológica. Essa estrutura é constituída ${ }^{32}$ pela unidade sintética de finitude-infinitude ou de particularidade-universalidade - dissolvida pelo plágio - e pela relação coexistencial ego-alter ego - dissolvida pela ofensa ao inocente. Plágio e

forçados ou à jornada exaustiva, quer sujeitando-o a condições degradantes de trabalho, quer restringindo, por qualquer meio, sua locomoção em razão de dívida contraída com o empregador ou preposto: Pena - reclusão, de dois a oito anos, e multa, além da pena correspondente à violência».

${ }^{32}$ Sobre isto, veja-se, mais amplamente, o meu Il diritto nell'esistenza, op. cit., cap. 3 . 
ofensa são, indubitavelmente, atos possíveis de liberdade, mas numa reciprocidade que os torna destrutivos de si mesmos e da liberdade.

Com os exemplos que foram dados, vai-se esclarecendo qual é o fundamento ontológico do direito natural: o eu-sintético-relacional. $\mathrm{O}$ eu é a fonte da liberdade por causa da sua tensão bipolar entre finito e infinito, ou particularidade e universalidade ${ }^{33}$; mas, ao mesmo tempo, é o limite da liberdade, pois se esta dissolve a sua unidade sintética, o eu cessa de ser, e com ele a liberdade.

Neste ponto, abrindo o olhar para além do direito, alcanço por meio do meu caminho ontofenomenológico a posição onto-axiológica de Campanale, ou da imanência do valor no ser ${ }^{34}$.

$\mathrm{Na}$ minha perspectiva, o eu-sintéticorelacional determina a estrutura constitutiva do ser-homem. Pois bem, considero aplicável a esse ser, mutatis mutandis, a definição dada por Kant ao "bem supremo" ou, como ele precisa, "originário" - palavra que tomo no sentido daquilo que dá origem, início -, pois é “a condição que é - ela mesma - incondicionada, isto é, não está subordinada a nenhuma outra condição" ${ }^{35}$. Eu disse mutatis mutandis: com efeito, o eu-sintético-relacional é condição incondicionada não simpliciter, mas secundum quid, isto é, relativamente ao mundo humano do compreender, pensar, agir. $\mathrm{O}$ eu-sintéticorelacional é a condição da história, da liberdade, da cultura, da sociedade, mas não é condicionado por elas, pois é a sua origem; condicionados por elas são os indivíduos existentes empíricos. Em sentido ontológico - e não somente lógicognosiológico - , eu faria minha a

\footnotetext{
${ }^{33}$ Aplico à estrutura ontológica do homem a dualidade de polos que caracteriza o método bergsoniano de explicação dos fenômenos. A propósito, elucidativo MATHIEU, Vittorio. Bergson: il profondo e la sua espressione. Napoli: Guida, 1971, especialmente o cap. 1.

${ }^{34}$ Cf. CAMPANALE, Domenico. Per una fondazione ontoassiologica del diritto. Milano: Angeli, 1986, mas, mesmo antes, IDEM. Scienza, ontologia e valore. Bari: Adriatica,
}

transcendentalidade do ego afirmada por Husserl com as precisões que indicarei mais adiante.

$\mathrm{Na}$ verdade, se se esquece ou se nega o ego condicionante, o mundo humano desvanece na incompreensibilidade, precipita no caos do conflito naturalista, e o ser não é mais ser-nós (homens), como é revelado pelo duplo sentido ambiental e pessoal da habitual tradução italiana de Dasein. Portanto, é legítimo reconhecer ao sersintético-relacional do homem o valor supremo, no sentido originário, que constitui o seu fundamento e, por isto, o critério universal do juízo sobre os possíveis humanos, uma vez que, parafraseando Leibniz, é o critério que permite determinar a "realidade possível" em relação à "essência" do homem ${ }^{36}$. Em suma, o homem é "digno" não por ser livre, mas por ser a origem ontológica do compreender, pensar, agir.

Neste ponto, impõem-se duas precisões ulteriores que determinam melhor a relatividade (secundum quid) da originária condição incondicionada e, por isto, da transcendentalidade que considero próprias do ego. Em primeiro lugar, o eu não é condição originária incondicionada (simpliciter) do ser do mundo nem de si mesmo (também não o é o indivíduo empírico!); tampouco é condição originária incondicionada da própria estrutura de ser: o eu não é causa sui, de modo que não pressupõe uma condição incondicionada simpliciter, que constitui a sua Origem e, por isto, o seu bem "perfeito", para usar a outra e distintiva qualificação kantiana do bem 37.

Disto se segue que a capacidade do ego de compreender, pensar e agir nunca é integral e terminativa, assim como a equação entre o seu ser e o bem não esgota este último. Na verdade, a

1963 e IDEM. Fondamento e problemi della metafisica: essere e verità. Bari: Adriatica, 1968.

${ }^{35}$ KANT, Emmanuele. Critica della ragion pratica. Trad. F. Capra. Bari: Laterza, 1955, p. 137 (partes I e II, cap. 2).

${ }^{36}$ Cf. LEIBNIZ, G. W. De rerum originatione radicali. In: IDEM. Saggi filosofici e lettere. Bari: Laterza, 1963, p. 79, organizado por Vittorio Mathieu.

${ }^{37}$ KANT. Critica della ragion pratica, op. cit., p. 137 
tensão à polaridade do infinito imanente no eu incita-o a buscar a libertação efetiva e não fantasmática da sua limitação. Aqui está a raiz da inquietude existencial do eu, que vem a ele do Infinito, que é extra me e in me ipso ao mesmo tempo, como afirma S. Agostinho ${ }^{38}$, Ser e Bem perfeito. Neste sentido, se se quer falar de finalismo do homem, seria oportuno esclarecer que se trata não apenas de um teleologismo genérico, mas, mais profundamente, de escatologismo.

Com estas observações, que requereriam um discurso muito mais amplo e articulado, lancei-me muito além dos confins do direito. Por isso, é preciso voltar a ele para concluir o discurso sobre o direito natural. $\mathrm{O}$ eu-sintético-relacional, enquanto condição incondicionada do agir mundano, é o fundamento e o critério universal da justificação da obrigatoriedade do direito empírico que o torna direito natural e o resguarda da exterioridade da imposição e do voluntarismo do poder, os quais frustram o seu sentido e a sua natureza. Considero que se pode (antes, que se deve) transferir para a estrutura do eu o que René Marcič, ao criticar a norma fundamental de Kelsen, atribuía ao direito natural: essa estrutura é o "a priori ontológico", e não meramente lógico, do direito; é a "não mensurada medida de toda medida" ${ }^{39}$.

Por marcar de modo normativo os limites ontológicos da liberdade individual e do arbítrio do legislador, o direito natural não comporta autocontradição. Ao contrário, revela a autocontradição da liberdade absoluta, tão irreal quanto o seu pressuposto ideológico: o eu absoluto.

\section{REFERÊNCIAS}

\section{AUGUSTINUS HIPPONENSIS. Confessiones.} De libero arbitrio.

BOBBIO, Norberto. Diritto e forza. In: IDEM. Studi per una teoria generale del diritto. Torino: G. Giappichelli, 1970.

CALABRÒ, Gaetano. Dilthey e il diritto naturale. Napoli: Morano, 1968.

CAMPANALE, Domenico. Fondamento e problemi della metafisica: essere e verità. Bari: Adriatica, 1968.

. Per una fondazione onto-assiologica del diritto. Milano: Angeli, 1986.

. Scienza, ontologia e valore. Bari: Adriatica, 1963.

CARCATERRA, Gaetano. La forza costitutiva delle norme. Roma: Bulzoni, 1979.

COTTA, Sergio. Giustificazione e obbligatorietà delle norme. Milano: Giuffrè, 1981.

Il diritto nell'esistenza: Linee di ontofenomenologia giuridica. Milano: Giuffrè, 1985.

\footnotetext{
${ }^{38}$ AUGUSTINUS HIPPONENSIS. Confessiones, XIII, 9, problema della scienza giuridica (1910-1935). Napoli: ESI, 8. 1987, p. 135.

39 MARCIČ, René. Reine Rechtslhre und klassische

Rechtsontologie, apud CARRINO, Agostino. Kelsen e il
} 
. L'uomo tolemaico. Milano: Rizzoli, 1975.

FREUD, Sigmund. L'Io e l'Es. Torino: Bollati Boringhieri, 1976.

HART, Herbert L. A. Il concetto del diritto. Trad. M. Cattaneo. Torino: Einaudi, 1965.

HEGEL, Georg, W. F. Lezioni sulla storia della filosofia. Trad. E. Codignola e C. Sanna. Firenze: La Nuova Italia, 1947.

HEIDEGGER, Martin. Kant e il problema della metafisica. Trad. M. E. Reina. Bari: Laterza, 1981.

HUSSERL, Edmund. Ricerche logiche. Vol. I. Milano: Mondadori, 1968.

KANT, Emmanuele. Critica della ragion pratica. Trad. F. Capra. Bari: Laterza, 1955.

KANTOROWICZ, Hermann. La definizione del diritto. Trad. Enrico di Robilant. Torino: G. Giappicchelli, 1962.

KELSEN, Hans. La dottrina pura del diritto. Trad. Mario G. Losano. Torino: Einaudi, 1960. Teorie generale delle norme. Trad. Mirella Torre. Torino: Einaudi, 1985.

LEIBNIZ, G. W. De rerum originatione radicali. In: IDEM. Saggi filosofici e lettere. Bari: Laterza, 1963.

LEVI, Alessandro. Scritti minori di filosofia del diritto. Vol. I. Padova: CEDAM, 1957.

LÖWITH, Karl. Critica dell'esistenza storica. Trad. A. L. Kunkler Giavotto. Napoli: Morano.

Marcič, René. Reine Rechtslhre und klassische Rechtsontologie, apud CARRINO, Agostino. Kelsen e il problema della scienza giuridica (1910-1935). Napoli: ESI, 1987.

MARINI, Giulano. Il giusnaturalismo nella cultura filosofica italiana del Novecento. In: MARINI, Giulano. Storicità del diritto e dignità dell'uomo. Napoli: Morano, 1987.

MARX, Karl; ENGELS, Friedrich. L'ideologia tedesca.

MATHIEU, Vittorio. Bergson: il profondo e la sua espressione. Napoli: Guida, 1971.

NIETZSCHE, Friedrich. Die Unschuld des Werdens.

PIOVANI, Pietro. Giusnaturalismo ed etica moderna. Bari: Laterza, 1961.

PLATÃO. Críton.

ROMMEN Heinrich. L'eterno ritorno del diritto naturale. Trad. Giovanni Ambrosetti. Roma: Studium, 1965.

SCARPELLI, Ugo. Gli orizzonti della giustificazione. Rivista di Filosofia, p. 1-50, 1985. 
Recebido em: 31/08/2017 Aceito em: 31/08/2017 
